\title{
Thermal Internal Boundary Layer characteristics at a tropical coastal site as observed by a mini-SODAR under varying synoptic conditions
}

\author{
Thara V Prabha ${ }^{1}$, R Venkatesan ${ }^{2}$ Erich Mursch-Radlgruber $^{3}$, G Rengarajan ${ }^{3}$ \\ N JAYANTHI ${ }^{4}$ \\ ${ }^{1}$ Crop and Soil Sciences, University of Georgia, GA, USA* \\ ${ }^{2}$ Health and Safety Division, SHINE Group, IGCAR, Kalpakkam, India 603102. \\ e-mail: rv@igcar.ernet.in \\ ${ }^{3}$ Boundary Layer Meteorology Division, Institut fuer Meteorologie und Physik (IMP-BOKU), Wien, \\ Austria. \\ ${ }^{4}$ India Meteorological Department, Chennai, India.
}

\begin{abstract}
Atmospheric boundary layer observations are conducted at a coastal site during a transition phase from winter to summer season over the Indian peninsula. Thermal Internal Boundary Layer (TIBL) characteristics in presence of an off-shore and a weakly influenced on-shore synoptic wind are examined with the help of measurements carried out with a mini-SODAR (SOund Detection And Ranging), tethered balloon, and tower-based micrometeorological measurements. Influence of the changing synoptic scale conditions on turbulent characteristics of TIBL is discussed.

Mini-SODAR data showed the development and decay of sea and land breeze. It is seen that the characteristics of TIBL over the coastal land after sea breeze onset are similar to that of a shallow convective boundary layer (CBL) commonly found over plain land. Inside the TIBL, a maximum wind speed was noted close to the surface due to the penetration of sea breeze. In the off-shore case, a distinct sea breeze circulation was observed unlike in the case of on-shore flow. In the presence of weak on-shore case, a 'minor sea' breeze is noted before the establishment of sea breeze and a reduction in the momentum fluxes gives rise to decrease in the turbulence intensity. Updraft in the sea breeze front was stronger during weak synoptic conditions. Influence of synoptic changes on the sea breeze-land breeze circulation such as onset, strength and duration of the sea-land breeze are also examined.
\end{abstract}

\section{Introduction}

Sea breeze is a local convective circulation developing as a direct effect of the differential heating between land and sea (Simpson 1987). The strength, horizontal and vertical extent of the sea breeze depends upon the prevailing synoptic flow, the land-sea surface temperature difference, and boundary layer temperature and moisture profile.

${ }^{*}$ This work was done while the first author was a visiting scientist at IGCAR, Kalpakkam, India.
Several researchers have noted that direction and strength of the synoptic flow influence the structure and evolution of sea breeze (Estoque 1962; Pielke 1974; Arritt 1993). The off-shore/on-shore wind velocity of the ambient flow influences inland penetration of the sea breeze. In the laboratory experiments conducted by Simpson (Simpson 1987) it was noted that the nature of prevailing gradient flow affects the development of sea breeze. Several theoretical studies (Pearson et al 1983; Garratt et al 1990; Bechtold et al 1991) have also been reported investigating the effects of large-

Keywords. Sea breeze; thermal internal boundary layer; turbulence; SODAR. 
scale wind fields on sea breeze circulation. The present study is an attempt to characterize the turbulence characteristics of TIBL during varying synoptic conditions at a tropical site.

During sea breeze situations, TIBL is formed over land with different diffusive characteristics inside and above the layer. Knowledge about some of these important characteristics is vital for various environmental impact assessment studies. Some of the important concerns in this regard are the fate of pollutants released inside the sea-land breeze circulation, the fumigation situations in the presence of TIBL and the presence of multiple inversion layers. Pollutants released near the coast can get entrapped in the closed land-sea breeze circulation emphasizing the need to study the fumigation aspect. Thus analysis of TIBL dispersion characteristics is essential for the study of dispersion in the presence of TIBL. Dispersion characteristics of TIBL decide the fate of pollutants released at the coast, and the aim of this study is to examine how the thermal and dynamical influence on the TIBL is altered during different synoptic winds.

Observational characteristics of sea breeze under weak synoptic influence have been reported using conventional instruments (Colacino and Dell'Osso 1978; Colacino 1982; Helmis et al 1987). Sea breeze front under different synoptic conditions have also been observed using various remote sensing techniques like Lidar (Banta et al 1993a), radar (Atkins and Wakimoto 1995, 1997) and SODAR (Helmis et al 1995b). Atkins and Wakimoto (1997) have discussed characteristics of the sea breeze front at on-shore, off-shore and parallel-flow situations. It is noted that under on-shore synoptic flow, the front is weak either due to weaker convergence at the front or due to delayed occurrence in the day when the thermal turbulent mixing is diminished (Estoque 1962; Pielke 1974; Arritt 1993; Atkins and Wakimoto 1995). Whereas for off-shore cases, the front is found to be very sharp and has relatively less inland penetration (Arritt 1993; Chiba et al 1999). Along with sea breeze, TIBL also gets modified under different synoptic conditions. Helmis et al (1995a) demonstrated thermal structure of sea breeze using facsimile records from an acoustic mini-sounder kept at the top of a $1000 \mathrm{~m}$ high mountain near to the coast. The elevated inversion layer was found to be the interface of the upper level synoptic flow and the sea breeze. Vertical velocity variance $\left(\sigma_{w}^{2}\right)$ profiles observed using the mini-SODAR showed dependence of $z^{2 / 3}$ as predicted by the free convection theory. A majority of these observational studies were focused on the mean characteristics of TIBL. Turbulence measurements inside the TIBL were measured in a few other studies (Smedman and Hoegstroem 1983; Ogawa et al 1986). Inside the TIBL, regions above one tenth of its depth was found to obey mixedlayer similarity (Prakash et al 1993). Direct measurements of turbulence structure inside the TIBL especially at tropical coastal sites are scarce and the present study will give some more insight into this aspect. In the present study, shallow convective boundary layer characteristics are studied by comparing it with CBL. Turbulence characteristics of TIBL at on-shore and off-shore synoptic wind are studied. Sea breeze frontal characteristics are also studied for these cases making use of highresolution data from mini-SODAR.

The acoustic remote sensing technique is extensively used for boundary layer research due to its ability to provide profiles of various atmospheric variables. The potential use of these remote sensors in the tropics is discussed for air pollution dispersion applications (Gera and Singal 1990; Singal et al 1994; Gera and Saxena Neeraj 1996). Singal et al (1986) reported the observations made at the east coast of India using an acoustic sounder and instrumented tower. They analyzed thermal structure of boundary layer up to $700 \mathrm{~m}$, which revealed the existence of elevated stratified layers during the sea breeze. Most of the studies (Rao 1992; Singal et al 1986) over the Indian coastal sites using acoustic sounder dealt with mean characteristics of sea breeze like onset, duration and vertical extent of sea breeze and effect of sea breeze on nocturnal boundary layer. Based on the low level wind maximum from acoustic sounder, Murthy et al (1996) derived Nocturnal Boundary Layer height. Prakash et al (1993) found that intensity of the sea breeze front is decided by the intensity and direction of the prevailing winds as well as the amount of rotation of the wind vector during the onset of the sea-breeze at Tumba on the west coast. Narayana Rao et al (1996) studied the climatology of wind patterns using a boundary layer SODAR at Kalpakkam. There is lack of information regarding the turbulent characteristics during the sea breeze occurrences and how the internal boundary layer gets modified under varying ambient flow. At this point, mini-acoustic sounders are state-of-the-art technology providing detailed information inside the TIBL. This study benefits from data collected from such a device, especially in the lower boundary layer with higher temporal and spatial resolution.

In this study, turbulent characteristics observed using a mini-acoustic sounder (Mursch et al 1993; Mursch and Wolfe 1993; Mursch et al 1996, 1997) at a tropical coastal site south of Chennai are presented. Unlike the boundary layer SODARs, mini-SODAR offers the possibility to have high frequency measurements at very fine vertical resolution in the surface layer. Tower-based conventional instruments are used to measure the 

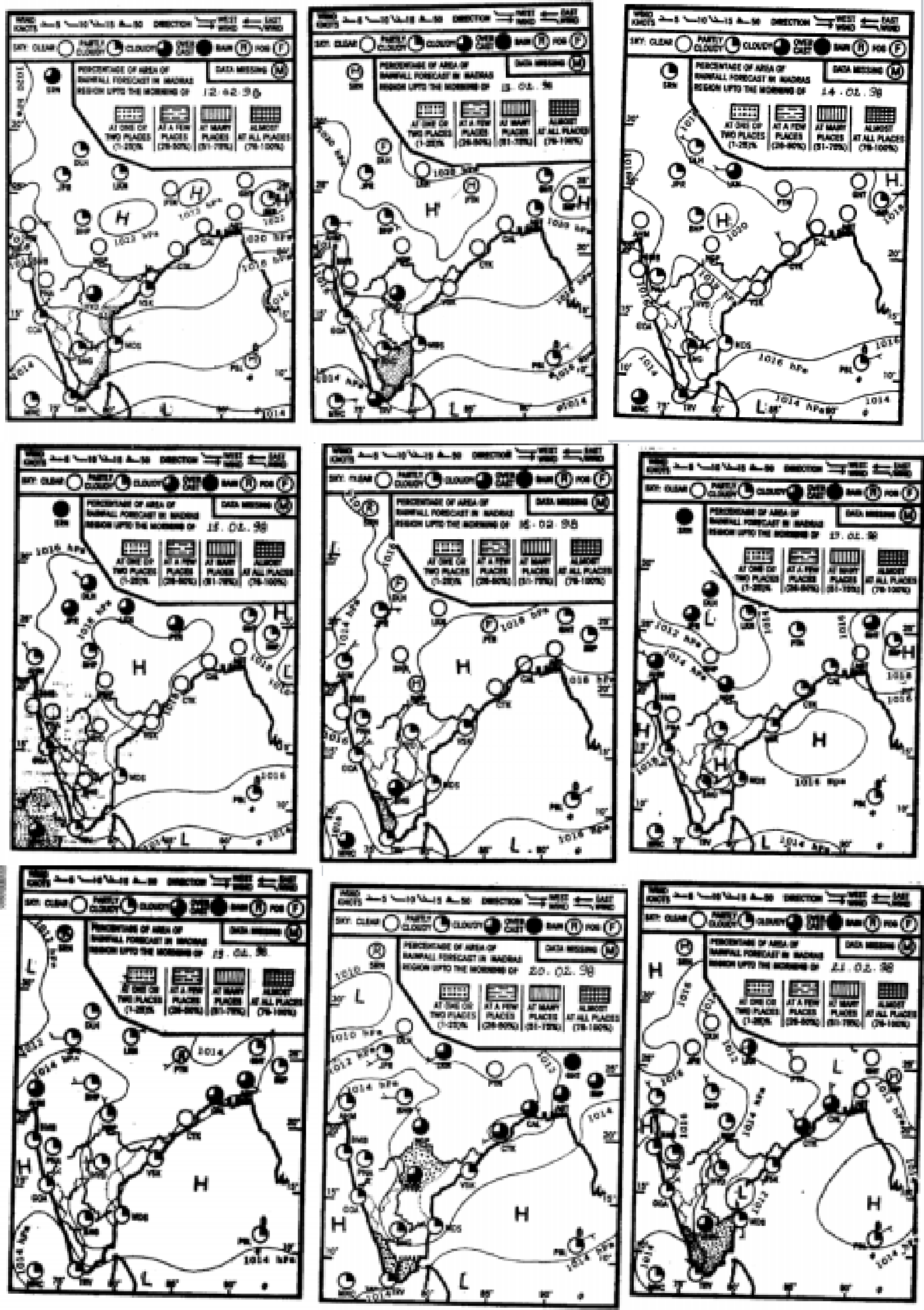

Figure 1. Synoptic maps during the measurement campaign (11th - 19th February 1998). Movement of high pressure towards sea and establishment of a low pressure over the peninsular region is the main characteristic during the measurement period. 
momentum and heat fluxes. This measurement was carried out during a change in pressure pattern during the winter to summer transition characterizing on-shore as well as off-shore synoptic conditions. The main objective of this study is to characterize the small temporal scale features of turbulence before, during and after the passage of sea breeze front. These characteristics are studied for varying synoptic conditions and its influence on various turbulence parameters is discussed. The study also considers the TIBL as a shallow convective layer and its similarity to a convective boundary layer is explored. The data are analyzed to gain more insight into the TIBL characteristics at various synoptic conditions during the experiment.

\section{Experiment and data}

In this section, detailed information regarding the site characteristics, experiment, data, and synoptic condition during the experiment is given. An analysis of synoptic condition is necessary as the focus of the study is in analyzing turbulence characteristics of TIBL during changing synoptic conditions.

\subsection{Measurement location and data}

Measurement site, Kalpakkam, lies on the east coast of southern Indian peninsula, $80 \mathrm{~km}$ south of Chennai. The coastline is linear and runs along SSW-NNE direction. The curvature of the coast has a slight influence on the sea breeze wind directions, which are mainly between east and southeast. This site is a flat terrain with low-rise bushes and grass, characterizing the land vegetation. MiniSODAR was located at a distance of $5 \mathrm{~km}$ inland. Mini-SODAR operates at 4 and $4.3 \mathrm{kHz}$ frequency covering an altitude of $200 \mathrm{~m}$ with a height resolution of $10 \mathrm{~m}$. Mini-SODAR was used for various surface boundary layer studies (Wölfelmaier et al 1999; Mursch and Rengarajan 1998; Mursch et al 2000). Measurements with a meteorological tower are made in an open plain ground close to the SODAR location. Mini-SODAR gives Fourier spectra of backscattered intensity profiles every $12 \mathrm{~s}$. Hourly mean and standard deviations of the wind components are computed from this data based on the Doppler shift. On the tower, wind components are measured at $10 \mathrm{~m}$ height, along with momentum and temperature flux. 3D Propeller Anemometers (Meteoscience, Austria) are used for velocity measurements with a frequency of $1 \mathrm{~Hz}$ at $10 \mathrm{~m}$ level. Temperature measurements are made at 2 and $10 \mathrm{~m}$ levels at a frequency of $1 \mathrm{~Hz}$ and every $15 \mathrm{~min}$ averages of mean, variance and covariance are stored in a datalogger (CR-21X, Cambell Scientific Inc.). Further details on these measurements and analysis can be found in Venkatesan et al (1999) and Prabha et al (2000).

Synoptic weather data are obtained from the Airport Observatory, IMD, Chennai, located northwest of the site at a distance of nearly $50 \mathrm{~km}$. The radiosonde site is $10 \mathrm{~km}$ inland from the east coast. Radiosonde data from this site comprises vertical profiles of wind, temperature and humidity. Daily weather report and surface pressure chart was also considered for the period of measurement.

\subsection{Synoptic situation during the experiment}

The measurements are carried out during the end of the winter season (10th-19th February 1998). High-pressure area existed over central India at the beginning of the measurement period (figure 1). The surface pressure chart showed a transition from winter to summer pressure pattern with gradual decrease of pressure over land. Due to the warming of the land, the high-pressure area over central India gradually moved eastward to Bay of Bengal (figure 1). Thereafter a low pressure (increase in temperature) was established over land by the end of the campaign. In the beginning of the period, 10th-13th February, a $2^{\circ} \mathrm{K}$ decrease was noted in maximum temperature (figure 2). A warming trend (up to $7^{\circ} \mathrm{K}$ ) was noted towards the end of the campaign. The wind pattern also showed changes accordingly. Surface weather data show gradual turning of the northeasterly synoptic wind to southwesterly wind with partly cloudy skies during the campaign. Initially an easterly/ northeasterly wind was noted which subsequently turned to southwesterly/southerly by 19th February. These characteristics clearly showed a winter to summer transition period over the study region associated with changing synoptic conditions.

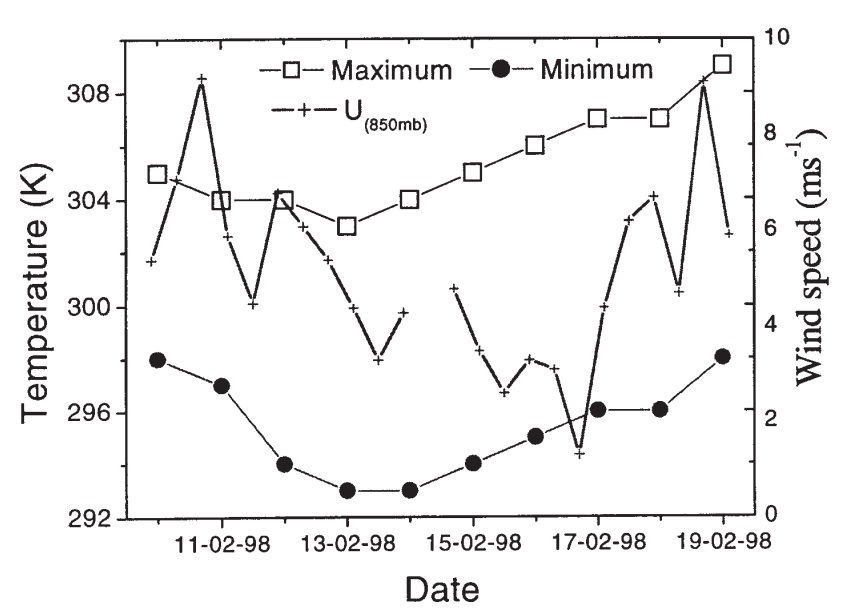

Figure 2. Minimum and maximum temperatures recorded at Chennai airport during the campaign. Wind speed observed at $850 \mathrm{mb}$ with the help of radiosonde profile is also shown. 


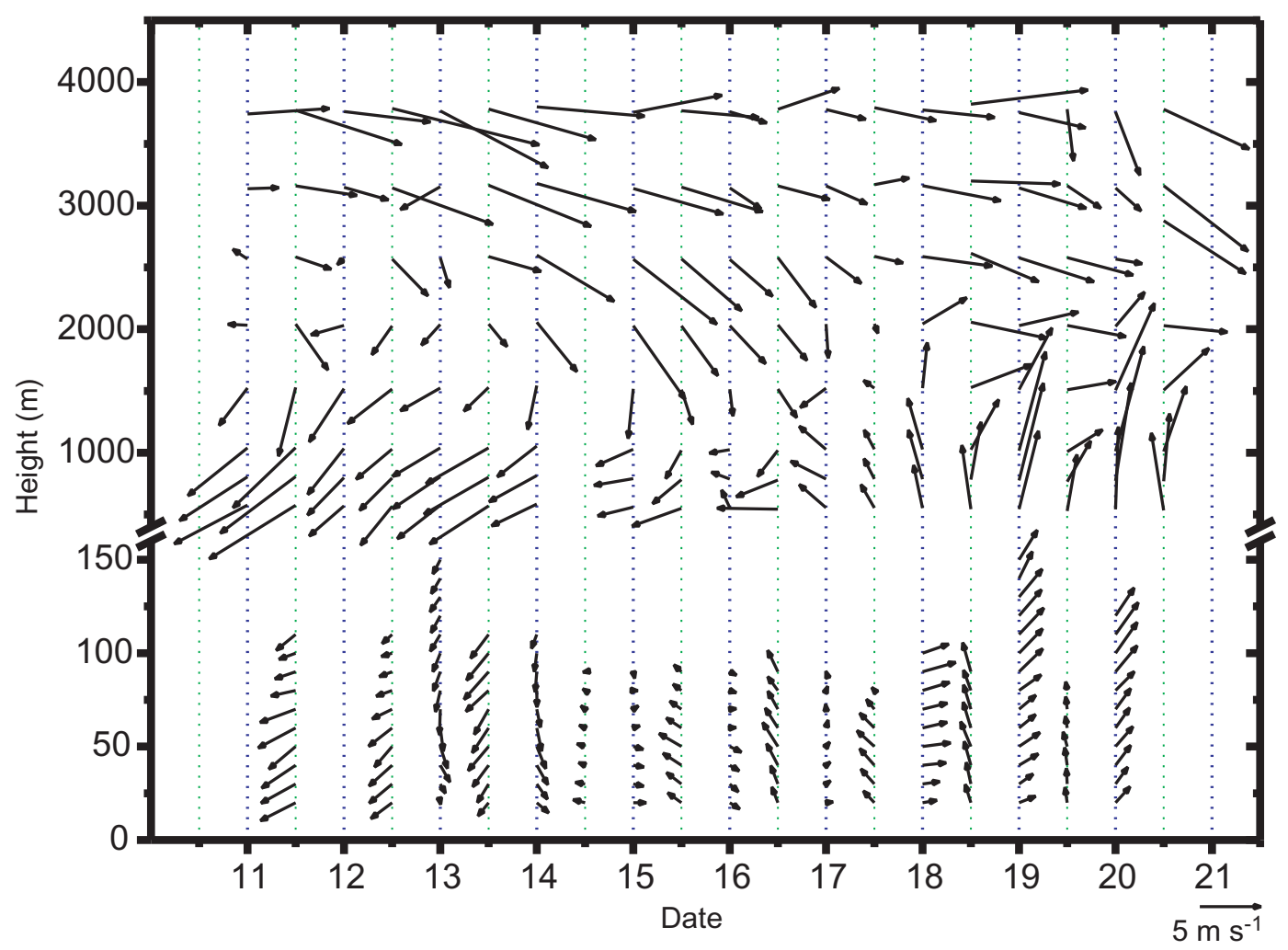

Figure 3. Composite wind profile from mini-SODAR and radiosonde. Lower part of the profile (up to $200 \mathrm{~m}$ ) is from mini-SODAR (hourly averaged corresponding to 0600 IST and 1600 IST) and from $500 \mathrm{~m}$ and above radiosonde profile (0615 IST and 1645 IST) is shown. Two profiles are shown for each day, first profile is corresponding to 0615 IST and the second profile to 1645 IST. Length of the arrows gives wind speed and direction is given by the orientation of arrows. The arrows are scaled with respect to $5 \mathrm{~ms}^{-1}$ scale given at lower right hand side corner of the plot.

\section{Results and discussion}

Radiosonde upper air data are available twice a day, 0615 IST and 1645 IST and are combined with the mini-SODAR wind data at lower levels for respective hours (figure 3 ). The figure shows that during the beginning of the experiment, the upper level winds are from northwest/west and northeasterly in the lower levels. The geostrophic wind for these days is northeasterly. The sea breeze strengthened northeasterly on-shore flow and the wind direction in the lower levels became easterly. In this case it is very difficult to distinguish the locally induced sea breeze from the prevailing synoptic on-shore flow. This situation prevailed till 16th February and the on-shore synoptic influence weakened thereafter. Gradually, due to the change in synoptic pressure, the lower level northeasterly wind weakened and became southeasterly (during 17th-18th February) and then southerly (during 19th-20th February). The entire period (11th-20th February) characterized a transition from post winter to the beginning of the hot season. Maximum and minimum temperature also revealed this (figure 2).

With respect to the local sea breeze observed with the mini-SODAR, the wind regime can be classified as aiding (on-shore) synoptic flow during 11th-16th February. During 14th-16th February, due to the weak synoptic influence, a welldeveloped sea breeze is noted from mini-SODAR data. Whereas, 17th-20th February data show transition of synoptic wind in the opposing (offshore) direction. Mini-SODAR data show stronger wind from the sea during this time compared to the beginning of the measurement period.

The mini-SODAR data of the lower level boundary layer wind velocity profiles show a maximum easterly/southeasterly winds in the evening profiles. This is attributed to the development of sea breeze. Radiosonde temperature profiles (not shown here for brevity) showed an associated neutral or unstable boundary layer over land with a stable layer aloft. This stable layer above the neutral/convective layer over land has developed as a result of maritime air coming over the land due to the sea breeze. The radiosonde temperature profile (not shown here) shows the presence of a strongly stable upper air during the first few days of the campaign and stable/weak stability in the boundary layer during the subsequent days in accordance with synoptic scale change.

Onset time, duration and strength of sea breeze as noted from the basic observations are given in 
Table 1. Sea breeze onset time, duration, strength, updraft, IBL height (derived from mini-SODAR data), temperature and relative humidity change associated with sea breeze onset at the coast (observed at Madras atomic power station meteorological tower) for the measurement period.

\begin{tabular}{lcccccccc}
\hline & $\begin{array}{c}\text { Onset } \\
\text { time } \\
(\mathrm{IST})\end{array}$ & $\begin{array}{c}\mathrm{U} \\
\left(\mathrm{ms}^{-1}\right)\end{array}$ & $\begin{array}{c}\text { Duration } \\
(\text { hours })\end{array}$ & $\begin{array}{c}\text { Updraft } \\
(\mathrm{w}) \\
\left(\mathrm{ms}^{-1}\right)\end{array}$ & $\begin{array}{c}\text { TIBL } \\
\text { height } \\
(\mathrm{m})\end{array}$ & $\begin{array}{c}\Delta \mathrm{T} \\
(\mathrm{K})\end{array}$ & $\begin{array}{c}\Delta \mathrm{T}_{\mathrm{L}-\mathrm{S}} \\
(\mathrm{K})\end{array}$ & $\begin{array}{c}\text { Relative } \\
\text { Humidity } \\
\text { change } \\
(\%)\end{array}$ \\
\hline 11th February* & - & 3.0 & 20 & 0.24 & 170 & 0.5 & 1.24 & - \\
12th February* & 900 & 2.6 & 19 & 0.27 & 220 & 2.0 & 0.53 & 10 \\
14th February & 1100 & 2.6 & 13 & 0.94 & - & 1.0 & 0.92 & 6 \\
15th February & 1000 & 2.8 & 15 & 2.58 & 160 & 2.7 & 1.2 & 12 \\
16th February & 1100 & 2.8 & 14 & 2.35 & 170 & 2.2 & 2.15 & 10 \\
17th February & 1100 & 2.9 & 15 & 1.48 & 150 & 1.0 & 2.08 & 10 \\
18th February & 1300 & 4.5 & 12 & 1.24 & 150 & -0.5 & 3.46 & 1 \\
19th February & 1300 & 4.6 & 12 & 1.03 & 170 & -0.5 & 3.43 & 1 \\
\hline
\end{tabular}

${ }^{*}$ Measurements are made at a location $500 \mathrm{~m}$ from the coast. For the remaining days measurements are carried out $5 \mathrm{~km}$ inland.

table 1. The TIBL height derived from SODAR vertical velocity variance profiles (as described in Appendix), temperature change associated with the sea breeze, difference of land-sea surface temperature maximum and relative humidity change at sea breeze onset at the shore are also given in the table. Except for the last two days, sea breeze onset occurred at late morning hours. Horizontal wind speed associated with the front is found to increase towards the end of the campaign. Sea breeze duration is found to be lesser for strong off-shore winds. The days with increased convective activity (15th and 16th February) and weak on-shore synoptic winds showed maximum vertical velocity of $2.5 \mathrm{~ms}^{-1}$ at $100 \mathrm{~m}$ level. TIBL height is between 150 and $200 \mathrm{~m}$ during the campaign. The temperature change and relative humidity change associated with the sea breeze is relatively higher during the weak synoptic influenced cases. It can also be noted from the table that, the land sea temperature difference increased towards the end of the campaign. This also explains stronger sea breeze by the end of the campaign.

\subsection{On-shore flow}

On-shore flow cases are classified for strong and weak synoptic scale winds respectively. In the case of on-shore strong flow, the presence of sea breeze as local circulation is not clearly noted in the horizontal wind velocity. Since the wind directions of synoptic flow and the sea breeze are the same, the local sea breeze only strengthens the ambient flow. High-resolution measurements from mini-SODAR shows detailed information on the changes during the onset of sea breeze. In the weak synoptic flow, a 'minor sea breeze' is noted before the establishment of the main sea breeze characterized by weak and variable wind. A similar feature was observed by
Banta et al (1993a) and Mastrantonio et al (1994). This transition period lasted for one to two hours. A gradual increase in wind speed followed by a slight change in wind direction was noted afterwards. Their study reports that this pattern was common to the days with weak on-shore flow. Similar features are observed in the present case as discussed below.

Mini-SODAR measurements of vertical and horizontal wind velocity for 16th February are given in figures 4(a) and (b). The onset of sea breeze occurred around 1140 IST. Bold arrows in the figure indicate the 'minor' sea breeze period. It is noted that the magnitude of horizontal and vertical velocities are comparatively less during this time. The occurrence of such minor sea breeze events also seem to be associated with the early onset. Due to diabatic heating during day time, temperature increased leading to a greater land-sea temperature gradient and increase in the strength of sea breeze towards the end of the 'minor' sea breeze period. Thermal instability seems to contribute to the enhanced sea breeze event followed by the minor sea breeze. Increase in wind speed was noted after the 'minor' sea breeze period, indicating the establishment of sea breeze. When the sea breeze gets established after this minor sea breeze period, vertical velocity increased up to $2 \mathrm{~ms}^{-1}$. At lower levels its magnitude is lesser. Vertical velocity increased and then decreased at regular intervals contributing to updrafts and downdrafts at all the vertical levels observed up to $100 \mathrm{~m}$. Updrafts are dominant at all the vertical levels with maximum around $100 \mathrm{~m}$. Downdrafts are weaker and are observed to be dominant in the lower levels. This pattern of up and down drafts gets repeated in $15 \mathrm{~min}$. intervals. These are indications of vertically elongated thermals, which transport heat and moisture upwards and periodic intrusion of mar- 


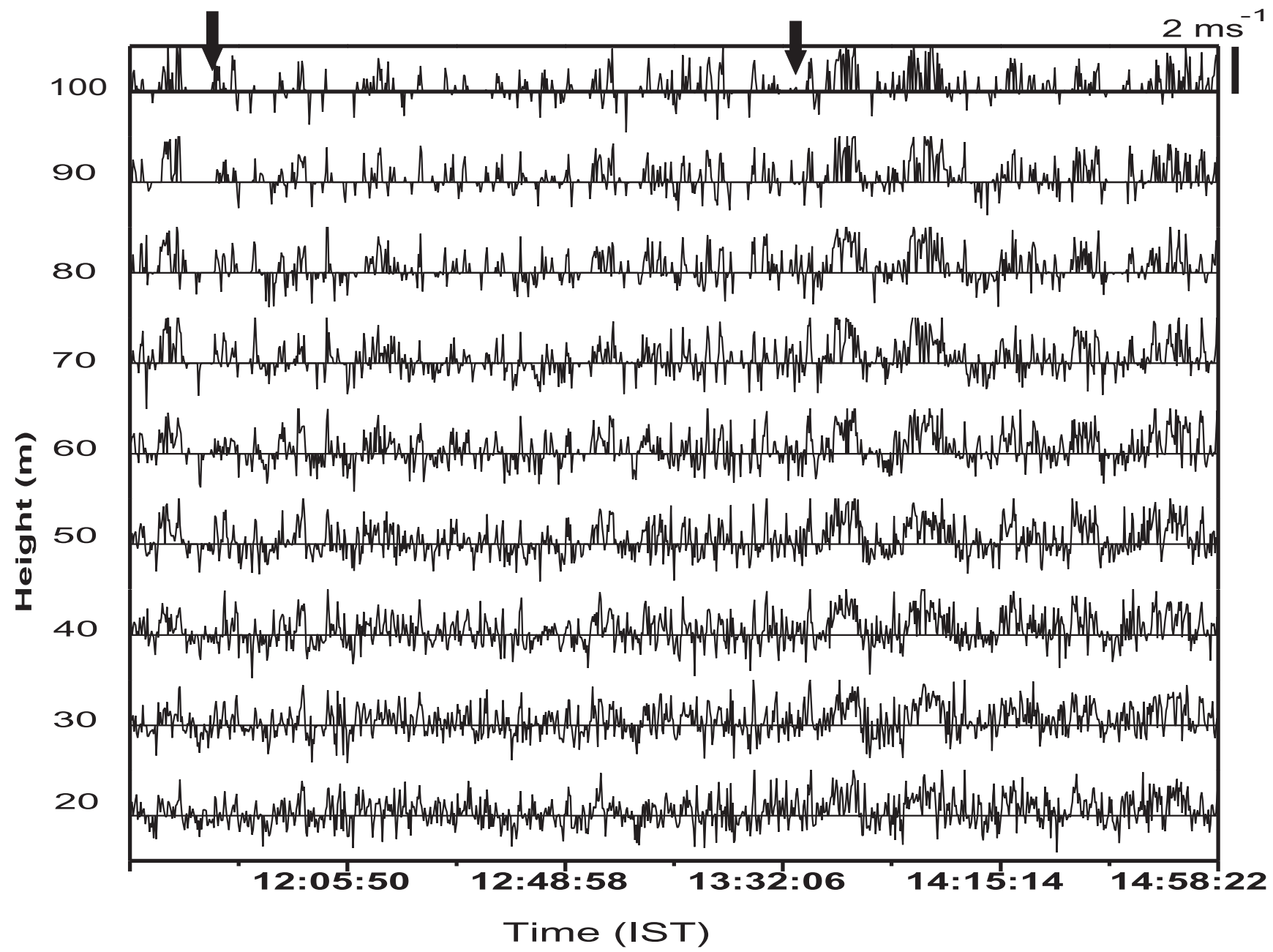

Figure 4(a). Profiles of vertical velocity from mini-SODAR for 16th February (on-shore case), during the sea breeze front and after the establishment of sea breeze. Time series with a temporal resolution of $12 \mathrm{sec}$ is shown with a vertical resolution of $10 \mathrm{~m}$ up to a height of $100 \mathrm{~m}$. The data are screened by signal to noise ratio criteria and the data points, which do not satisfy this criterion, are not plotted. Minor sea breeze period is marked with thick arrows at the top of the plot. After minor sea breeze period, gravity wave activity is seen in the vertical velocity time series at all vertical levels.

itime air over the heated land. The horizontal wind velocity showed a more orderly pattern during this time with changes in wind direction from SE to S. Similar features appear in the SODAR facsimile as buoyancy waves having their periods ranging between 5 and 15 min and amplitudes between 100 and $150 \mathrm{~m}$ (Rao et al 1992) associated with either surface-based inversions or elevated layers or rising inversions.

Measurements of temperature and momentum fluxes made at a $10 \mathrm{~m}$ tower are presented in figure 5(a) along with temperature measurements at 10 and $2 \mathrm{~m}$ levels. The horizontal wind changed from southwesterly land breeze to southeasterly sea breeze flow. TIBL characteristics associated with the sea breeze front and after the passage of the front are examined with the help of this data. Wind characteristics and standard deviation of vertical velocity $\left(\sigma_{w}\right)$ are also examined from mini-SODAR. TIBL-characterized wind maximum at lower levels can be attributed to the penetration of sea breeze.

\subsubsection{During the sea breeze front passage}

Temperature flux variation showed an increase (figure 5a) in association with the onset of sea breeze. It can be noted that the onset is at $1140 \mathrm{hrs}$ and the arrival of sea breeze did not cool the lower atmosphere considerably (only a slight decrease in heat flux is noted), instead, the rate of warming diminished. This is attributed mainly to combined effects of warming due to continued increase in solar radiation and decrease in air temperature due to the intrusion of cooler air. Another fact to be considered is that the marine air is already in contact with warming land because of the on-shore synoptic wind for a considerable period before the local breeze reached $5 \mathrm{~km}$ inland. Temperature at $10 \mathrm{~m}$ showed an increase and the difference between 10 and $2 \mathrm{~m}$ levels widened to $-1.5^{\circ} \mathrm{K}$, thus the instability increased gradually. The magnitude of this increase in instability is found to be nearly the same for all on-shore flow cases considered except 




Figure 4(b). Profiles of horizontal velocity from mini-SODAR for 16th February (on-shore case), during the sea breeze front and after the establishment of sea breeze. The data are screened by signal to noise ratio criteria and the data points, which do not satisfy this criterion, are not plotted. Time series with a temporal resolution of 12 sec is shown with a vertical resolution of $10 \mathrm{~m}$ up to a height of $100 \mathrm{~m}$. Length of the arrow gives wind speed and the direction is given by orientation of arrows. There is considerable alteration in the wind speed and direction, which is synchronous with variations in vertical velocity, through out the period shown. Minor sea breeze period characterizes lower wind speeds and increased turbulence.

some difference in the time of occurrence. When there was delay, especially due to the slow warming up of the land, sea breeze was not well defined during that period. Due to the weak sea breeze during this time, cooling due to advection of air from the sea is considerably less and is surpassed by the increase in diabatic heating. At this stage, the temperature gradients between land and sea would not have been sufficient for a sudden surge of the sea breeze event, rather weakening it and leading to 'minor' sea breeze event.

During the frontal passage, an initial increase in the friction velocity was seen indicating increase in wind shear. Immediately after that, the momentum flux decreased and thermal driving mechanism dominated in the TIBL. Decrease in momentum flux is found to be more for weaker on-shore flow cases and especially during the 'minor sea breeze' cases. In the vertical profile of $\sigma_{w}$ (figure $5 \mathrm{~b}$ ), considerably lower values (at 1200 IST, between 40 and $120 \mathrm{~m}$ above the surface) are noted during the sea breeze frontal passage, which happened to be the 'minor sea breeze' period. This decrease in $\sigma_{w}$ is attributed to the decrease in turbulence generated by wind shear. Decrease in $\sigma_{w}$ values during the front passage is seen throughtout the TIBL depth. Since the momentum flux has decreased during this time, contribution from shear production to turbulence is relatively less. Turbulence is produced mainly by the buoyant production (by thermals) during this time. In figure 5(b), all the profiles show an increase in $\sigma_{w}$ with height up to $100 \mathrm{~m}$ level, followed by a decrease beyond that level, representing the shallow convective layer characteristics.

\subsubsection{After the passage of sea breeze front}

After the sea breeze frontal passage, the temperature difference between 2 and $10 \mathrm{~m}$ levels narrowed to $-1^{\circ} \mathrm{K}$ (figure $5 \mathrm{a}$ ). This is mainly attributed to 


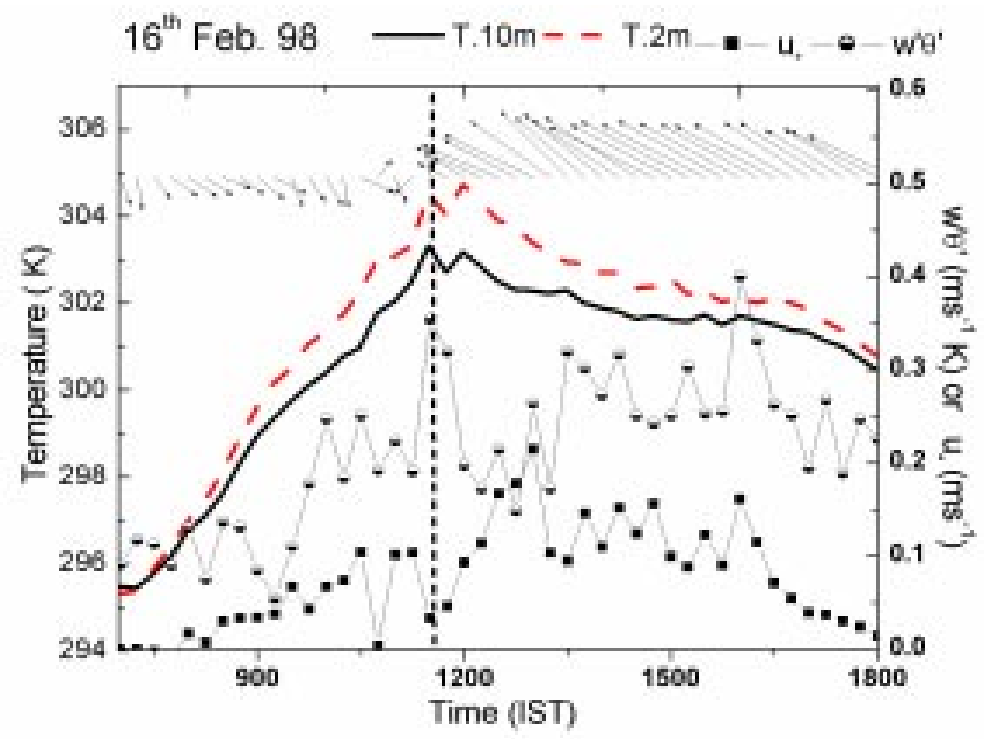

Figure 5(a). Variation of friction velocity $\left(u_{*}\right)$, temperature flux $\left(Q_{0}=\overline{w^{\prime} \theta^{\prime}}\right)$ and potential temperature measurements at 10 and $2 \mathrm{~m}$ on 16 th February, on-shore weak wind condition. 15 min averages are shown.

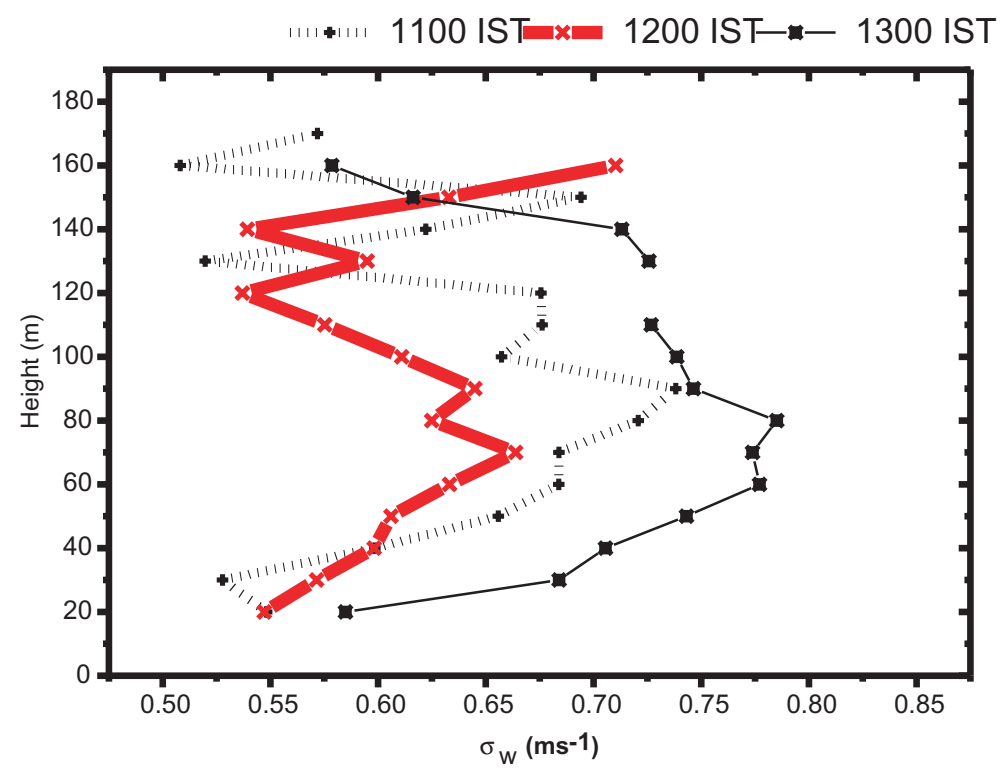

Figure 5(b). Vertical profiles of vertical velocity variance $\left(\sigma_{w}\right)$ during and after sea breeze frontal passage for 16 th February. Sea breeze onset was at 1100 IST.

be the increased intrusion of cool air from the sea. Increase in the sea breeze strength during this period is associated with increased temperature gradients between land and sea. Unlike noted in the other studies (Helmis et al 1995a; Asimakopoulos et al 1996) turbulence intensity increased after the passage of the front around 1300 IST as seen in figure 5(b). This increase is attributed to the production of turbulence by buoyant thermals. Meanwhile, mean wind shear after the passage of the sea breeze front also increased and contributed to mean kinetic energy within the TIBL as can be seen from figure 5(a), where there is considerable increase in momentum flux after 1300 hours. In a study con- ducted at the west coast of India (Thumba) it was observed that the structure of TIBL during an onshore case indicated similar dominance of mechanical turbulence (Kunhikrishnan et al 1993).

Vertical profile of $\sigma_{w}$ shows a maximum around $100 \mathrm{~m}$ as noted during the passage of the front. This is similar to a bell shaped profile of convective boundary layer depicting the shallow convective layer characteristics.

\subsection{Off-shore case}

Synoptic wind $(850 \mathrm{mb}$ wind is considered here) was off-shore westerly for the last two days (18th 


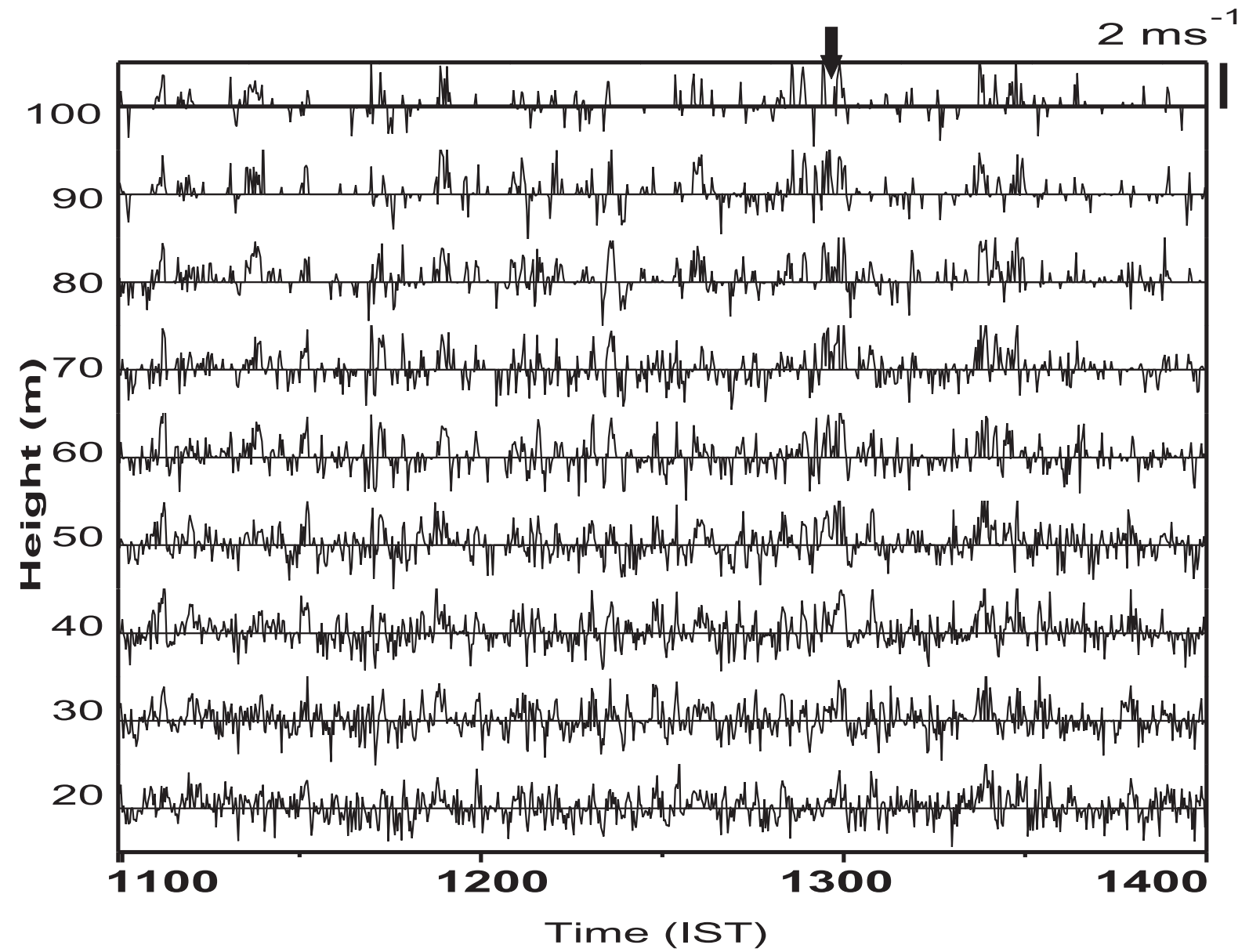

Figure 6(a). Profiles of vertical velocity time series with a temporal resolution of 12 sec is shown from mini-SODAR for 18 th February (off-shore case), during and after the onset of sea breeze. Vertical velocities are lower compared to 16th February.

and 19th February) of the campaign as can be noted from figure 3 . The wind direction changed to $\mathrm{SE}$ in the lower levels due to the influence of sea breeze. Wind velocities observed using miniSODAR during the sea breeze onset of 18th February is given in figures 6(a) and (b). Rapid development of sea breeze is clearly noted in the vertical as well as the horizontal wind velocities. Vertical velocity showed alternate increasing and decreasing trend with weaker updrafts than in the earlier case of on-shore weak flow. This is an indication that the contribution from buoyant thermals is lesser. Moreover the peaks in the updrafts are having longer periods and are not well defined as in the on-shore case.

There is an increase in land-sea temperature difference (table 1) in association with increased warming. Relatively higher temperature gradient resulted in a stronger sea breeze. Sharply defined sea breeze onset and increased turbulence intensity characterize these off-shore synoptic wind cases. Sea breeze sets late in the afternoon and its duration is also comparatively lesser than the on-shore case. Whereas, observed vertical temperature gradient between 10 and $2 \mathrm{~m}$ levels was lower (figure 7a) in magnitude compared to the on-shore case. These differences are mainly at the time of onset, which is associated with the cooling introduced by the sea breeze. Once the sea breeze is established, these vertical temperature gradients are nearly equal during on-shore and offshore cases. Unlike in the on-shore case, the onset occurred in the afternoon hours and is strong and rapid leading to immediate reduction in temperature gradient. Thus convective activity is quickly suppressed with the onset of sea breeze in contrast to the weak on-shore synoptic case. 'Minor sea breeze' seems to be associated only with weak on-shore cases and is not observed for this case.

Vertical profiles of $\sigma_{w}$ for off-shore case are given in figure $7(\mathrm{~b})$. Turbulence intensity values are comparatively higher than those observed during the on-shore weak wind situations and are mainly attributed to increased wind shear associated with higher wind speeds after the front. This is in conformity with similar observations at Thumba. As an indication of this, friction velocity varied from 0.4 to $0.5 \mathrm{~ms}^{-1}$ during this time (figure $7 \mathrm{a}$ ). These values are found to be higher than that noted during on-shore weak wind conditions $(0.2-0.3 \mathrm{~m} / \mathrm{sec})$. This explains the increase in $\sigma_{w}$ after the onset of 


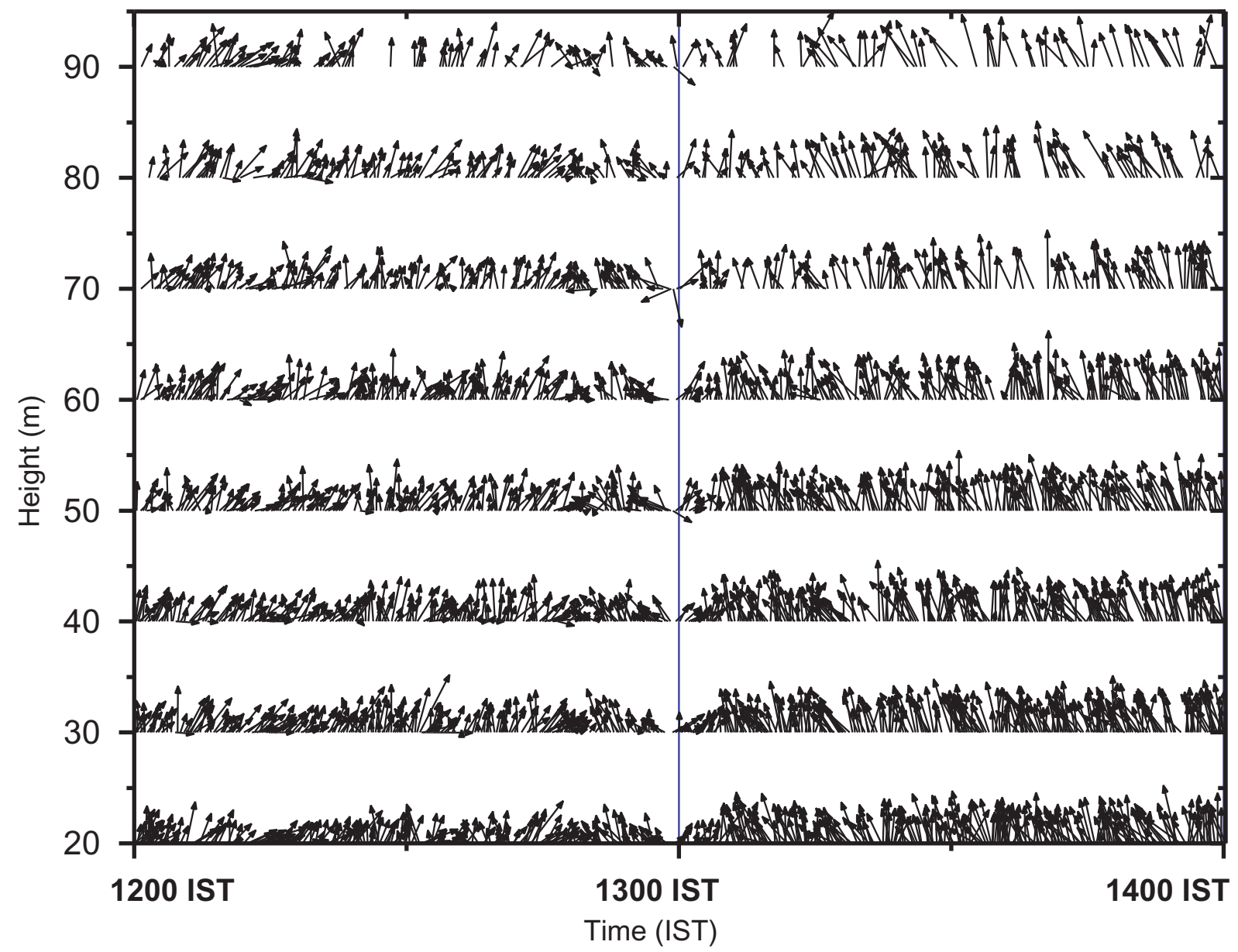

Figure 6(b). Profiles of horizontal velocity from mini-SODAR for 18th February (off-shore case), during and after the onset of sea breeze. Time series with a temporal resolution of $12 \mathrm{sec}$ is shown with a vertical resolution of $10 \mathrm{~m}$ up to a height of $100 \mathrm{~m}$. The occurrence of sea breeze is sudden and the front is sharp as the associated changes in wind speed and direction are without a minor sea breeze.

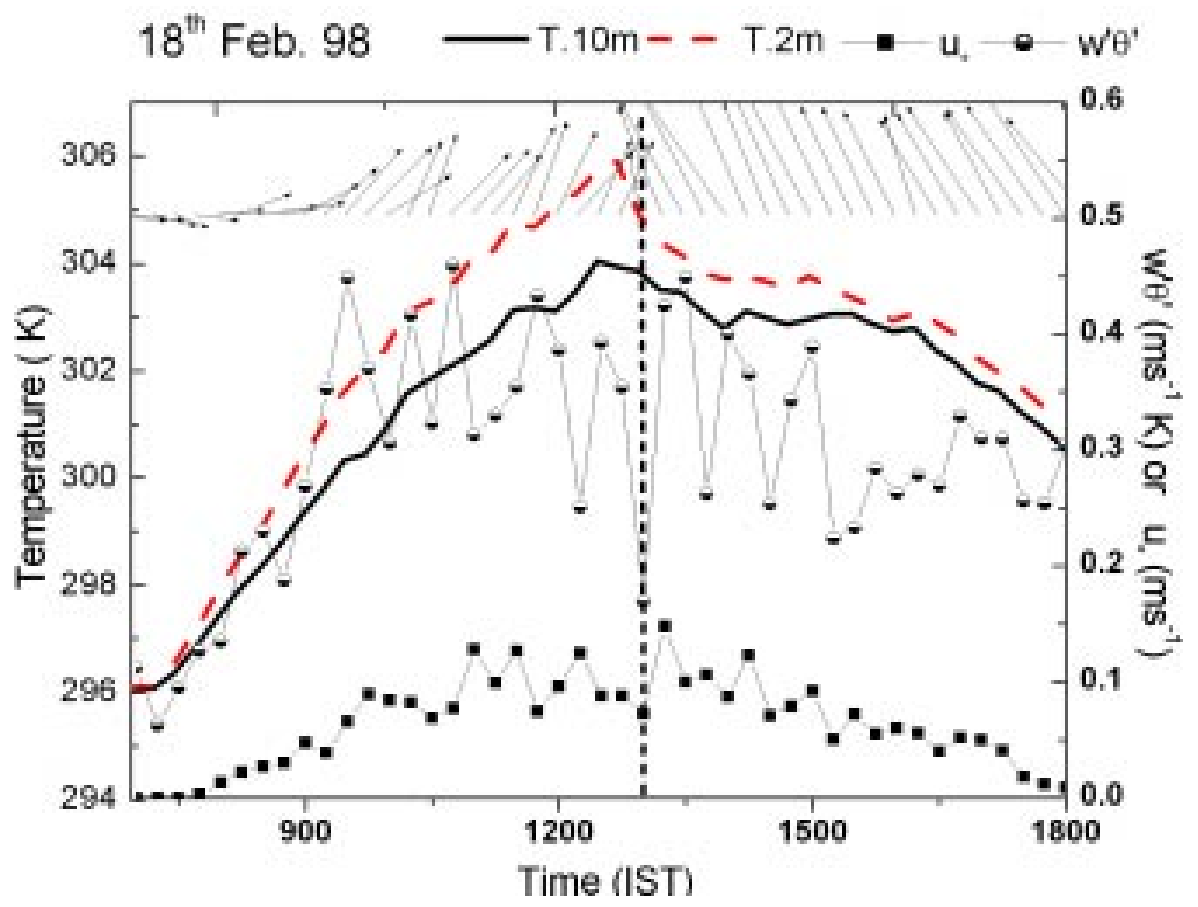

Figure 7(a). Same as figure 5(a) but for 18th February, off-shore case. 


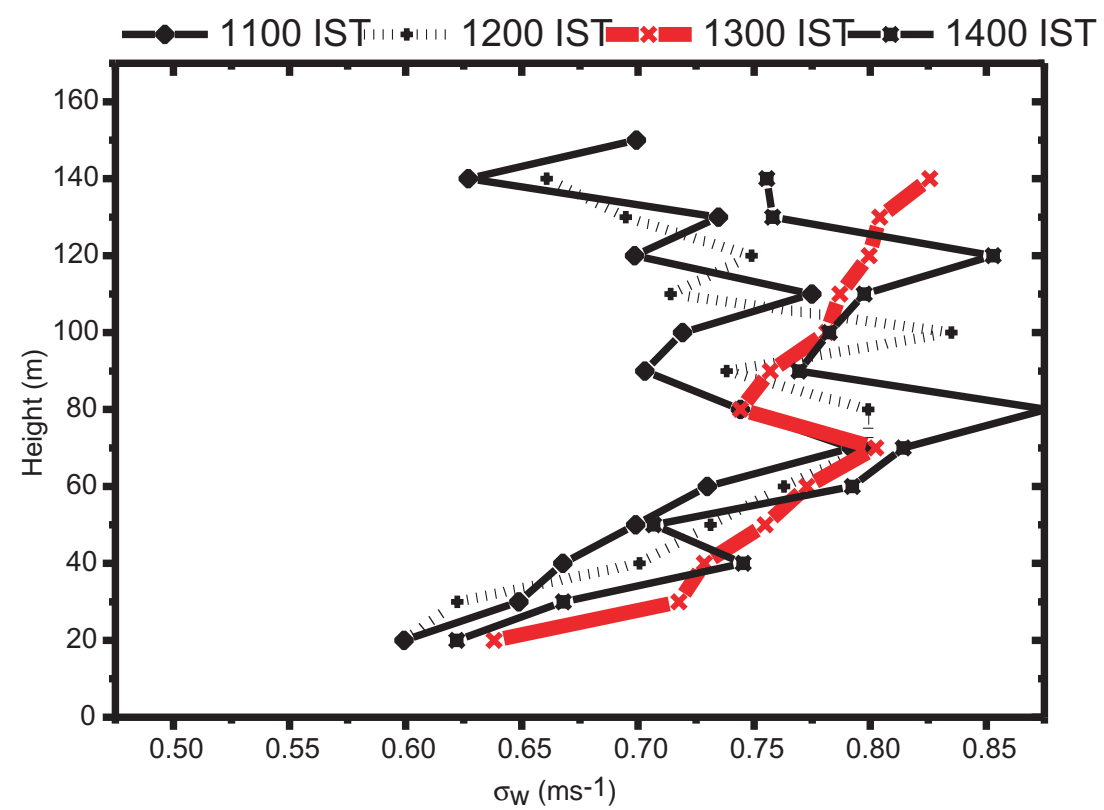

Figure $7(\mathrm{~b})$. Vertical profiles of vertical velocity variance $\left(\sigma_{w}\right)$ before, during and after sea breeze frontal passage for 18 th February offshore case. Sea breeze onset was at 1300 IST.

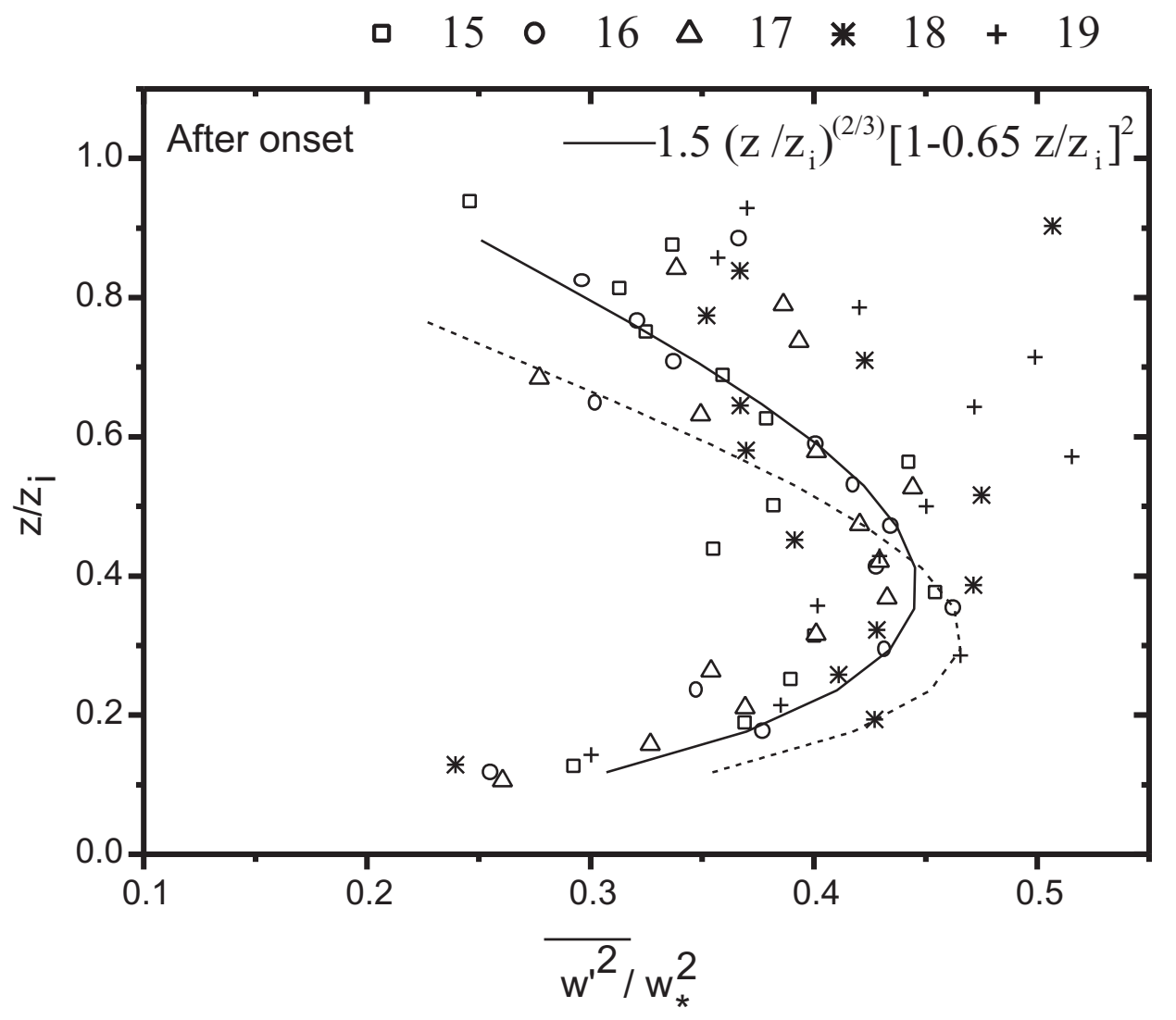

Figure 8. Turbulence intensity after the onset of sea breeze. Both $X$ and $Y$ axis in this plot are normalized with respective scaling parameters. $Y$-axis is scaled with TIBL height and $X$-axis is scaled with convective scaling velocity derived from temperature flux and the TIBL height. Standard convective boundary layer parameterization for vertical distribution of turbulence intensity from vertical velocity is compared with that of a shallow convective layer (TIBL). Broken line represents $\frac{\overline{w^{\prime 2}}}{\overline{w_{*}^{2}}}=1.8\left(z / z_{i}\right)^{2 / 3}\left(1-0.8 z / z_{i}\right)^{2}$ and solid line represents best fit for the data for 15th and 16th February. 
sea breeze and thereafter, which is noted through out the TIBL. Further increase in $\sigma_{w}$ is associated with the enhanced mechanical turbulence after passage of the sea breeze front. Similar features are observed in the 19th February case also where similar synoptic conditions prevailed.

Turbulence intensity profiles after the sea breeze onset is given for all the five days of measurement (figure 8). Scaling parameters used in the plot are the convective scaling velocity $w_{*}$ and the TIBL height $z_{i}$. Weill (1980) discussed a method to find inversion height from the vertical velocity variance profiles for shallow convective layers. Accordingly, vertical velocity variance is directly proportional to heat flux for shear free shallow convective layers. In the heat flux profile, minimum heat flux corresponds to the TIBL height. This was again validated with the help of tethersonde temperature profiles. In the present study the surface value of temperature flux $\left(Q=\overline{w^{\prime} \theta^{\prime}}\right)$ and TIBL height are used to find convective scaling velocity $\left(w_{*}\right)$ using the mixed layer relation $w_{*}=\left(\frac{g}{T} Q_{0} z_{i}\right)^{1 / 3}$. More detailed description of this method can be found in Prabha et al (2000) and is briefly described in the Appendix. Turbulence intensity profiles presented in figure 8 includes on-shore and off-shore cases considered above. It can be seen that the bell shaped profile is a characteristic feature except for 18th and 19th February. As discussed earlier, wind shear dominates for off-shore synoptic wind cases and TIBL growth is mainly controlled by the wind shear. Whereas for on-shore cases, a shallow convective layer profile of turbulence intensity is observed, below $0.5 z / z_{i}$, turbulence intensity is found to be lesser than that of a convective mixed layer and above $0.5 z / z_{i}$, turbulence intensity is higher than that of the mixed layer. The higher values above $0.5 z / z_{i}$, indicate increased entrainment and wind shear dominance. Kunhikrishnan et al (1993) found reasonable agreement only up to 0.3 to $0.4 z / z_{i}$, beyond which lesser values of turbulence intensity were observed compared to that for the convective boundary layer and they attributed it mainly to the wind structure.

\section{Conclusion}

The unique feature of this study is the use of high frequency data of vertical velocity from miniSODAR in conjunction with flux measurements at a $10 \mathrm{~m}$ tower. The experiment was carried out during a changing synoptic condition from winter to summer pressure pattern over the Indian subcontinent. Sea breeze structure and TIBL turbulence characteristics are discussed based on observations during weak on-shore and strong off-shore synoptic winds. It is observed that the onset time and duration of sea breeze is closely associated with the synoptic forcing. Updrafts associated with the sea breeze front are found to be stronger $\left(2 \mathrm{~ms}^{-1}\right)$ and turbulence intensity is lower during the weak onshore synoptic wind case. It is also found that buoyancy driven turbulence characterize the "minor sea breeze' observed before the establishment of the main sea breeze during the on-shore case. There is considerable reduction in the turbulence intensity during the minor sea breeze case, mainly due to decrease in wind shear and also partly due to the decreased instability over land. Wind shear increased after the passage of the front and along with buoyancy driven turbulence, thus contributing increase in turbulence intensity. After the onset, the turbulence intensity is found to increase generally in both on-shore and off-shore cases. The turbulence intensity associated with the strong offshore case is higher (figure 8) than that of the weak on-shore case. Kunhikrishnan et al (1993) also have compared turbulent parameters inside TIBL with that of a convective boundary layer. They found reasonable comparisons up to a height of $0.3-0.4 z / z_{i}$. In the present study, these comparisons showed lower values in the lower part (below $\left.0.4 z / z_{i}\right)$ of TIBL and higher values above. These differences seem to be associated with the depth of the TIBL, on-shore/off-shore synoptic flow and its interaction with the development of TIBL.

The importance of this study is centered on identifying the change in turbulence characteristics inside the TIBL associated with changes in synoptic condition. The study of turbulence characteristics and the interaction between the two scales of atmospheric dynamics at different synoptic forcing will be helpful for understanding the frontal characteristics and are useful in air pollution dispersion modeling. Unlike in previous studies (Prakash et al 1993; Kunhikrishnan et al 1993) with the help of structure function from boundary layer SODAR, the present study derives TIBL height from vertical velocity variance inside and above TIBL. Differences between the on-shore and off-shore synoptic influence on TIBL thermal and dynamical character is evident in high frequency data from the tower and mini-SODAR data. The changes associated with the variability in the synoptic scale is significant and is to be considered for the dispersion model calculations, since they are found to influence the thermal as well as diffusive characteristics of the TIBL. Unlike previous studies, mini-SODAR data of higher vertical and temporal resolution, which enabled identification of features like minor sea breeze found to be a characteristic feature of weak on-shore flow. This has also enabled the possibility to compare TIBL characteristics to that of a shallow convective layer. 
These observations are made at a single location and are inadequate to deliver any information on the horizontal extent of the sea breeze. Nevertheless, turbulence characteristics during minor sea breeze noted in this study might have implications for off-shore dispersion, especially because the vertical mixing is suppressed and there is relatively low wind shear which can lead to short term stagnation situations. The duration of such events can have more significance for ground level pollutant sources. Such events with shorter temporal scale can easily get unnoticed in pollution forecasting studies. Further study is needed to prove the significance of these minor sea breeze events on dispersion of pollutants. A unique tracer experiment is underway at this site to accumulate data and validate the transport and diffusion models in this regard, which will look into the horizontal extent of sea breeze front and its turbulence characteristics at various distances inland.

\section{Acknowledgement}

We thank Mr. George Mursch-Radlgruber and Dr. $\mathrm{K}$ Anandakumar for the experimental setup and data acquisition. We also thank Dr. A Natarajan, Head, Health and Safety Division, IGCAR and Mr. K M Somayaji for the constant encouragement to carry out this work.

\section{APPENDIX}

The fluxes and variances are derived directly from time series of $u, v, w$ and $\theta$ at a temporal resolution of $1 \mathrm{sec}$.

Vertical velocity $(w)$ variance is given by

$$
\sigma_{w}^{2}=\frac{1}{N} \sum_{i=0}^{N-1}\left(w_{i}-\bar{w}\right)^{2},
$$

$N$ is the number of data points during an averaging time.

Covariance in the flux relations is calculated based on the relation

$$
\operatorname{Cov}(u, w)=\overline{u^{\prime} w^{\prime}}=\frac{1}{N} \sum_{i=0}^{N-1}\left(u_{i}-\bar{u}\right)\left(w_{i}-\bar{w}\right) .
$$

Friction velocity $\left(u_{*}\right)$ is found from the covariance of $u, w$ and $v, w$ and is given by

$$
u_{*}^{2}=\left[\overline{\left(u^{\prime} w^{\prime}\right)^{2}}+\overline{\left(v^{\prime} w^{\prime}\right)^{2}}\right]^{1 / 2} .
$$

Temperature flux is given by

$$
Q=\overline{w^{\prime} \theta^{\prime}} .
$$

In a shallow convective layer, if the mechanical (shear) production is negligible, vertical velocity variance is related to the temperature flux as (Weil et al 1980)

$$
\frac{\sigma_{w}^{3}}{z} \approx \beta \frac{g Q}{\bar{T}},
$$

where ' $\beta$ ' is a constant, ' $T$ ' temperature ' $g$ ' acceleration due to gravity and ' $z$ ' is the height above the surface. Plot of temperature flux versus $z$ is generally used to find the surface temperature flux and mixing height of convective boundary layers. The extrapolated value of temperature flux at the surface $(z=0)$ is the surface temperature flux $\left(Q_{0}\right)$. TIBL height $\left(z_{i}\right)$ can be estimated as the height of zero temperature flux obtained by linear extrapolation of temperature flux profile.

The surface temperature flux and the TIBL height is then used to find the convective scaling velocity $\left(w_{*}\right)$ using the mixing layer relationship

$$
w_{*}=\left(\frac{g}{T} Q_{0} z_{i}\right)^{1 / 3} \text {. }
$$

\section{References}

Arritt R W 1993 Numerical modeling of the offshore extent of sea breezes; Quart. J. Roy. Meteor. Soc. 115 547-570

Asimakopoulos D N, Helmis C G and Petrakis M 1996 MiniAcoustic sounding - a powerful tool for ABL applications: recent advances and applications of acoustic miniSODARs; Boundary-Layer Meteorol. 81 49-61

Atkins N T and Wakimoto R M 1997 Influence of the synoptic scale flow on sea breezes observed during CaPE; Mon. Weather Rev. 125 (9) 2112-2130

Atkins N T, Wakimoto R M 1995 Observations of sea breeze front during CaPE. Part II: Dual Doppler and aircraft analysis; Mon. Weather Rev. 123 944-969

Banta R M, Oliver L D and Levinson D H 1993a Evolution of the Monterey Bay sea breeze layer as observed by pulsed Doppler lidar; J. Atmos. Sci. 50 3959-3982

Bechtold P, Pinty J P and Mascart P 1991 Numerical investigation of the influence of large scale winds on sea breeze and inland breeze type circulation; J. Appl. Meteorol. 30 $1268-1279$

Chiba O, Kobayashi F, Naito G and Sassa K 1999 Helicopter observations of the sea breeze over a coastal area; J. Appl. Meteorol. 38 481-492

Colacino M and Dell' Osso L 1978 The local Atmospheric circulation in the Rome Area: Surface observations; Boundary-Layer Meteorol. 14 133-151

Colacino M 1982 Observation of sea breeze events in Rome area; Arch. Meteorol. Geoph. Biok. Bd 30 127-139

Estoque M A 1962 The sea breeze as a function of the prevailing synoptic situation; J. Atmos. Sci. 19 244-250

Garratt J R, Pielke R A, Miller W F and Lee T J 1990 Mesoscale model response to random surface based perturbations - a sea breeze experiment; Boundary-Layer Meteorol. 52 313-334

Gera B S, Saxena Neeraj 1996 Sodar data - a useful input for dispersion modeling; Atmospheric Environment, 30 (21), 3623-3631 
Gera B S, Singal S P 1990, Sodar in air pollution meteorology; Atmospheric Environment 24A (8-2), 2003-2009

Helmis C G, Asimakopoulos D N, Deligiorgi D G and Lalas D P 1987 Observations of sea breeze fronts near the shoreline, Boundary-Layer Meteorol. 38 395-410

Helmis C G, Papadopoulos K H, Kalogiros J A, Soilemes A T and Asimakopoulos D N 1995a Influence of background flow on evolution of saronic gulf sea breeze; Atmospheric Environment 29 (24) 3689-3701

Helmis C G, Kalogiros J A, Asimakopoulos D N, Papadopoulos K H and Soilemes A T 1995b Acoustic Sounder Measurements of Atmospheric Turbulent Fluxes on the Shoreline; Global Atmos. Ocean System 2 351-362.

Kunhikrishnan P K, Gupta K S, Ramachandran R, Prakash J W, Nair K N 1993 Study on thermal internal boundary layer structure over Thumba, India; Annales Geophysicae-atmospheres Hydrospheres and Space Sciences 11 (1) 52-60

Mastrantonio G, Viola A P, Argentini S, Fiocco G, Giannini L, Rossini L, Abbate G, Ocone R and Casonato M 1994, Observations of sea breeze events in Rome and the surrounding area by a network of Doppler SODARs; Boundary-Layer Meteorol. 71 67-80

Mursch-Radlgruber E and Rengarajan G 1998 Aspects of high frequency acoustic sounding - examples from applications of the BOKU mini-SODAR; Proceedings of the 9th international symposium on acoustic remote sensing and associated techniques of the atmosphere and oceans ISRAS' 98, Vienna, Austria 103

Mursch-Radlgruber E and Wolfe D E 1993 Mobile high frequency mini-SODAR and it's potential for boundary layer studies; Appl. Phys. B 57 57-63

Mursch-Radlgruber E, Gregg D W, King C W, Ruifieux D, Sharp K A K, Wolfe D E, Neff W D 1993 NOAA's portable high frequency Mini Sodar Design and first results; Int. J Remote Sensing 25 (2) 325-332.

Mursch-Radlgruber E, Rengarajan G, Mursch-Radlgruber G, 1996 Discussion of multi-beam multi-frequency miniSODAR operation; 8th Int. Symposium on Acoustic Remote Sensing and Associated Techniques of the Atmosphere and Oceans ISARS '96. 27-31 May, (ed) M A Kallistratova, Moscow, Russia.

Mursch-Radlgruber E, Leclerc M Y, Prabha T, Karipot A, Gepp W 2000 Evaluation of Multi-Beam Multi Frequency Sodar Techniques for Turbulence Measurements; 10th Symposium on Acoustic Remote Sensing, Auckland, NZ, 26th Nov-1st Dec.

Mursch-Radlgruber E, Neff W D, Rengarajan G, Russel C 1997 Shallow mixed layer during drainage condition along the front range; 12th AMS Symposium on Boundary Layer and Turbulence, July 28 - August 1, Vancouver, Canada. Poster.

Murthy B S, Dharmaraj T, Vernekar K G 1996 SODAR observations of the nocturnal boundary layer at Kharagpur, India; Boundary-Layer Meteorol. 81 201209
Narayana Rao D, Krishna Reddy K, Vijaya Kumar T R, Kishore P 1996 Wind climatology observed over Kalpakkam using Doppler sodar; Indian Journal of Radio Es Space Physics, 25(3) 115 0367-8393

Ogawa, Y, Ohara T, Wakamatsu S, Diosey P G and Uno I 1986 Observation of lake breeze penetration and subsequent development of the thermal internal boundary layer for the NANTICOKE II shoreline diffusion experiment; Boundary-Layer Meteorol. 35 207-230

Pearson R A, Carboni G and Brusasca G 1983 The sea breeze with mean flow, Q. J. R. Meteorol. Soc. 109809 830

Pielke R A 1974 A three-dimensional numerical model of the sea breezes over south Florida; Mon. Weather Rev. $102115-139$

Prabha T V, Anandakumar K, Venkatesan R and Somayaji K M 2000 Coastal Atmospheric Boundary Layer Experiment (CABLE-98); IGC-213 Report on site specific parameters. Health and Safety Division, IGCAR, Kalpakkam. (Available from L\&IS, IGCAR, Kalpakkam, 603 102, India)

Prakash J W, Ramachandran R, Nair K N, Gupta K S, Kunhikrishnan P K 1993 On the spectral behaviour of Atmospheric Boundary Layer parameters at Thumba, India; Q. J. R. Meteorol. Soc., 119 (509A), 187-197

Rao D N, Ravi K S, Rao S V, Kumar T R, Murthy M J, Pasricha P K, Dutta H N, Reddy B M 1992 A qualitative study of wave motions in atmospheric boundary layer observed over Thirupati using SODAR; Indian Journal of Radio \&3 Space Physics, 21(2) 134-140

Simpson J E 1987 Gravity Currents: In the environment and the laboratory; (John Wiley and Sons)

Singal S P, Gera B S, Pahwa D R 1994 Application of sodar to air pollution meteorology; International Journal of Remote Sensing, 15(2) 427-441

Singal S P, Aggarwal S K, Pahwa D R, Gera B S 1986 Acoustic sounding: A tool for monitoring air pollution hazards; Indian Journal of Environmental Health, 28(1), $48-53$

Smedman A and Ulf Hoegstroem 1983 Turbulent characteristics of a shallow convective internal boundary layer; Boundary-Layer Meteorol. 25 271-287

Venkatesan R, Prabha T V and Somayaji K M 1999 Coastal Atmospheric Boundary Layer Experiment (CABLE-98); IGC-206, Report on Measurements and Data Presentation. Health and Safety Division, IGCAR, Kalpakkam. (Available from L\&IS, IGCAR, Kalpakkam, 603 102, India)

Weill A, Klapisz C, Strauss B, Baudin F, Jaupart C, Van Grundebeeck P and Goutorbe J P. 1980 Measuring Heat Flux and Structure Functions of Temperature Fluctuations with an Acoustic Doppler Sodar; J. Appl. Meteorol. 19 199-205.

Woülfelmaier F A, King C W, Mursch-Radlgruber E, Rengarajan G 1999 Mini-Sodar Observations of Drainage Flows in the Rocky Mountains; Theor. Appl. Climatol. $641 / 2,83-91$ 